Bull. Mater. Sci., Vol. 16, No. 6, December 1993, pp. 699-707. (C) Printed in India.

\title{
Effect of humidity on the breakdown strength and diffusion characteristics of polymer film
}

\author{
M M HOSSAIN \\ Department of Applied Physics and Electronics, Rajshahi University, Rajshahi, Bangladesh \\ MS received 27 October 1992; revised 21 September 1993
}

\begin{abstract}
Dielectric breakdown strength and diffusion characteristics were measured for polyimide and polyimide fluorocarbon polymer film at different weathering conditions. The dielectric breakdown strength and the diffusion coefficient were found to decrease in humid conditions. Different diffusion characteristics as well as breakdown mechanisms were observed on both sides in the PMF-1 polymer film. The permeation coefficient and diffusion coefficient decrease, thereby increasing the breakdown strength in more humid conditions that may be due to the formation of double potential well in the polymer film.
\end{abstract}

Keywords. Breakdown strength; permeation; diffusion; weathering; potential well; clustering.

\section{Introduction}

The use of polymeric materials in outdoor insulating systems has significant advantages over that of conventional inorganic materials. Insulators made from inorganic materials did not offer any problem concerning deterioration due to weathering. Polymeric insulators however, may be subjected to ageing process, caused by the surrounding conditions.

If electronic parts or circuits are coated or sealed with polymers, it is necessary to consider electrical properties, adhesive property, thermal conductivity, chemical resistivity, etc. (Yamaguchi 1981). Consideration of water vapour permeability in the sealing materials is also regarded as essential.

At higher test temperatures or if much water has diffused into the specimens, the amount of heat caused by dielectric losses leads to breakdown due to thermal instability. The measured values of the breakdown voltage of polymers are greatly influenced by the surrounding conditions. In practice, it is important to know whether the electrical strength of the polymer is reduced to a value close to service stress by absorbed water. The rate of water absorption depends on the kind of polymer and the environmental conditions.

The aim of the present work was to study the effects of humidity on dielectric breakdown strength and diffusion characteristics of PM, PMF-351 and PMF-352 polymer films.

\section{Experimental}

Three types of polymeric materials are investigated here to study the breakdown and diffusion phenomenon of such materials under different operating conditions. The investigated materials are commercial-grade polyimide known as PM (Yslovia 1972) and two kinds of polyimide fluorocarbon films ( $10 \mu \mathrm{m}$ fluorocarbon- $-40 \mu \mathrm{m}$ polyimide 
and $10 \mu \mathrm{m}$ fluorocarbon $-30 \mu \mathrm{m}$ polyimide $-10 \mu \mathrm{m}$ fluorocarbon sandwich film, commercially known as PMF-351 and PMF-352) (Yslovia 1983), of thickness $40 \mu \mathrm{m}$, $50 \mu \mathrm{m}$ and $50 \mu \mathrm{m}$ respectively. The specimens were square, with $8 \mathrm{~cm}$ sides. After washing with alcohol, aluminium electrodes of $15 \mathrm{~mm}$ dia. were deposited on both surfaces of film by vacuum evaporation. Electrode configuration is used here to perform uniform field which is attained by using two similar brass spheres each of $15 \mathrm{~mm}$ dia. The spacing between the two electrodes can be smoothly controlled to hold the specimen tightly. The experiment was carried out in air under ac voltage of frequency $50 \mathrm{~Hz}$ obtained from a high voltage generating circuit. The voltage applied to the specimen under test for determining the breakdown strength was gradually increased at a constant rate of $0-5 \mathrm{kV} / \mathrm{sec}$ till the breakdown occurred. Ten specimens were used for each reading of breakdown voltage of the polymer materials mentioned.

Permeation method based on the vacuum system was used for studying diffusion in polyimide and polyimide fluorocarbon polymer films. A typical vacuum permeation apparatus is shown schematically in figure 1. Its main element is a glass permeation cell in which the test specimen is placed. Attached to the permeation cell are the following: a source of vapour, a coulometer (X-603), a U-shaped mercury manometer, and a conventional high-vacuum system of pumping with an oil diffusion pump. All the elements of the permeation apparatus are accommodated in an air thermostat, while the permeation cell is provided with a thermostating jacket.

The permeation process is performed using integral method (Malkin et al 1983). In this method, the initial pressure in each permeation test is zero, i.e. when running each test, the pressure changes from zero to the present value $\left(5 \times 10^{-3}\right.$ torr).

Before the investigation, the samples were placed in the weather chamber at different conditions, i.e. $20^{\circ} \mathrm{C}+65 \%$ R.H., $40^{\circ} \mathrm{C}+95 \%$ R.H. and $20^{\circ} \mathrm{C}+95 \%$ R.H. for 3 and 6 months. The experiment was also carried out under the same conditions. The accuracy of the weather chamber was $\pm 1{ }^{\circ} \mathrm{C}$ for temperature and $\pm 2 \%$ for relative humidity (R.H.).

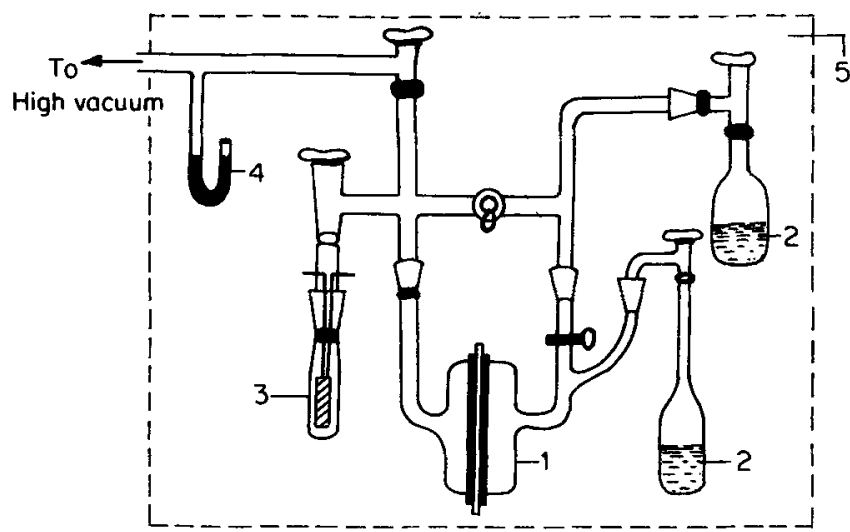

Figure 1. Vacuum permeation apparatus. 


\section{Results and discussion}

It is well known that water affects the dielectric breakdown strength of insulators. The absorption of water is associated with the chemical and physical properties of insulators. The absorption of water is also associated with the chemical structure of insulators, hydrophilic radicals $\left(-\mathrm{COOH},-\mathrm{H},-\mathrm{NH}_{2}\right.$, etc.), defects and voids.

The dielectric breakdown strengths of PM, PMF-351 and PMF-352 polymer film are shown in table 1 . It is observed from the table that the dielectric breakdown strengths of PM and PMF-352 polymer film of thickness $40 \mu \mathrm{m}$ and $50 \mu \mathrm{m}$ at normal conditions $\left(20^{\circ} \mathrm{C}+65 \%\right.$ R.H. $)$ are around $9.7 \mathrm{kV}$ and $12.0 \mathrm{kV}$ respectively but $9.7 \mathrm{kV}$ and $9.8 \mathrm{kV}$ respectively after 3 or 6 months under the more humid conditions of $20^{\circ} \mathrm{C}+95 \%$ R.H. Thus the dielectric breakdown strength of PM polymer film is constant throughout all the weathering conditions imposed but that of PMF-352 decreases from $12.0 \mathrm{kV}$ to $9.8 \mathrm{kV}$ after 3 months in humid conditions and then it is constant. In the case of PMF-351 polymer film of thickness $50 \mu \mathrm{m}$, the dielectric breakdown strength decreases from $9.2 \mathrm{kV}$ at normal conditions $\left(20^{\circ} \mathrm{C}+65 \%\right.$ R.H. to $8.5 \mathrm{kV}$ and then to $7.4 \mathrm{kV}$ after 3 and 6 months at $20^{\circ} \mathrm{C}+95 \%$ R.H.

Figures 2, 3 and 4 show the time-dependent failure probability in Weibull plots for PM, PMF-351 and PMF-352 polymer films at the different weathering conditions. It is observed from the figures that the time for failure probability is less $20^{\circ} \mathrm{C}+95 \%$ R.H. than at normal conditions $\left(20^{\circ} \mathrm{C}+65 \%\right.$ R.H. $)$ for PM, PMF-351 and PMF-352. An important point is that for PM and PMF-352 polymer films the time for failure probability at $40^{\circ} \mathrm{C}+95 \%$ R.H. is less than that at normal conditions and more than that at $20^{\circ} \mathrm{C}+95 \%$ R.H., but for PMF-351 polymer film this is not true.

The decreasing trend of breakdown strength in humid conditions can be explained in terms of thermal breakdown whose reason is considered as follows. Sufficient water molecules are present in the polyimide and polyimide fluorocarbon polymer film which assist the ionic dissociation of impurities under electric stress. Accordingly,

Table 1. Dielectric breakdown strength of polyimide (PM) and polyimide fluorocarbon (PMF-351 and PMF-352) polymer films at different weathering conditions.

\begin{tabular}{|c|c|c|c|}
\hline & \multicolumn{3}{|c|}{ Breakdown strength } \\
\hline & \multirow[b]{2}{*}{$\begin{array}{l}\text { Normal conditions } \\
20^{\circ} \mathrm{C}+65 \% \text { R.H. }\end{array}$} & \multicolumn{2}{|c|}{$\begin{array}{l}\text { Humid conditions } \\
20^{\circ} \mathrm{C}+95 \% \text { R.H. }\end{array}$} \\
\hline & & $\begin{array}{l}\text { kept for } \\
3 \text { months }\end{array}$ & $\begin{array}{l}\text { kept for } \\
6 \text { months }\end{array}$ \\
\hline $\begin{array}{l}\text { Polyimide } \\
(\mathbf{P M})\end{array}$ & $9 \cdot 7 \pm 1 \cdot 20$ & $9 \cdot 7 \pm 1 \cdot 20$ & $9 \cdot 7 \pm 1 \cdot 20$ \\
\hline $\begin{array}{l}\text { Polyimide } \\
\text { fluorocarbon } \\
\text { PMF-351 }\end{array}$ & $9 \cdot 2 \pm 0 \cdot 80$ & $8.5 \pm 0.80$ & $7 \cdot 4 \pm 0.40$ \\
\hline $\begin{array}{l}\text { Polyimide } \\
\text { fluorocarbon } \\
\text { PMF-352 }\end{array}$ & $12 \cdot 0 \pm 0.80$ & $9 \cdot 80 \pm 0.60$ & $9 \cdot 80 \pm 0.50$ \\
\hline
\end{tabular}






Figure 2. Time dependent failure probability in Weibull plots for PM polymer film at different humid conditions, $V=2 \mathrm{kV}$.

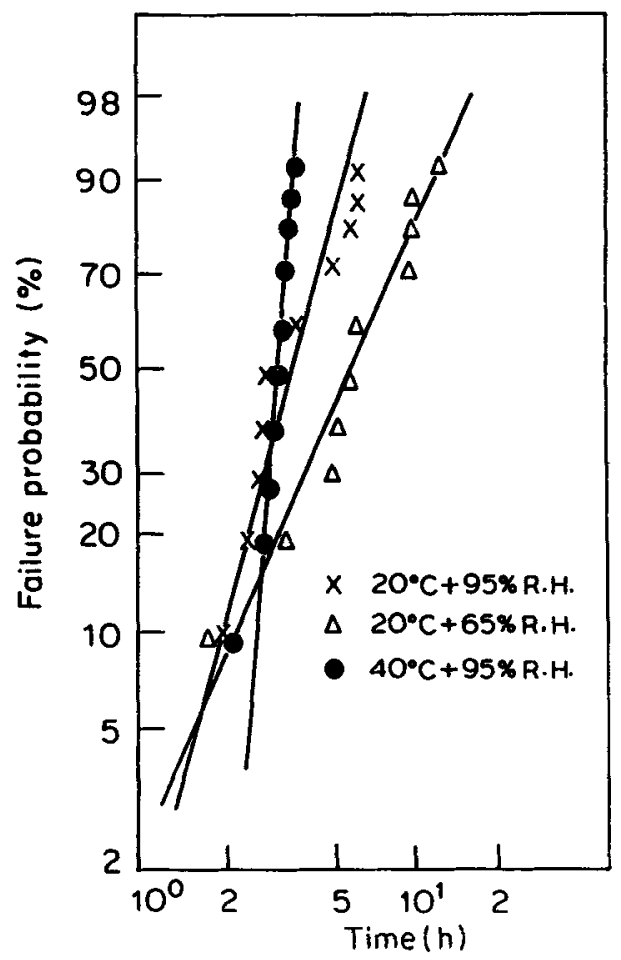

Figure 3. Time dependent failure probability in Weibull plots for PMF-351 polymer film at different humid conditions, $V=2 \mathrm{kV}$. 


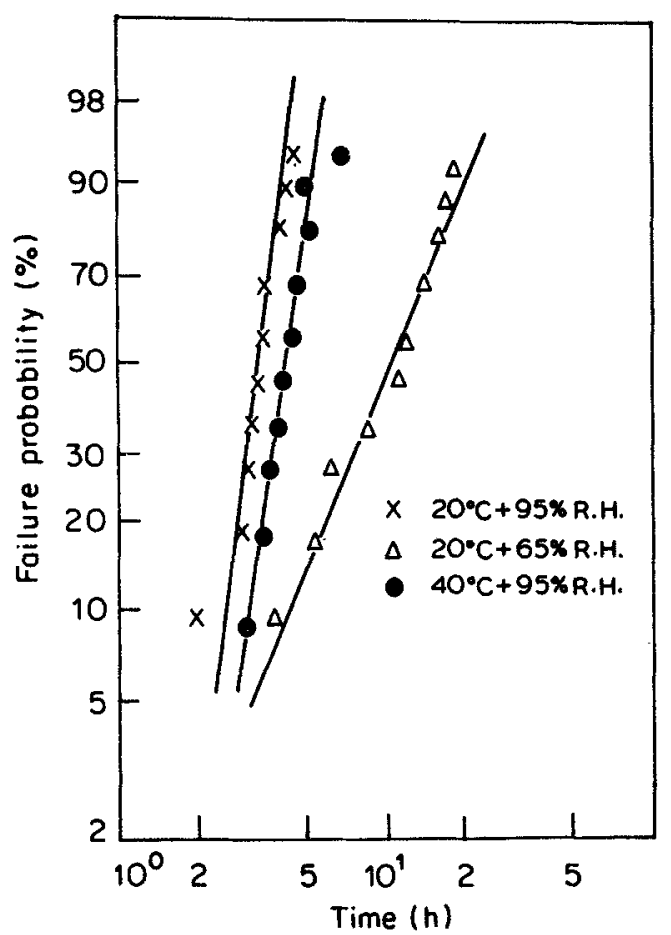

Figure 4. Time dependent failure probability in Weibull plots for PMF-352 polymer film at different humid conditions, $V=2 \mathrm{kV}$.

electrical conduction is increased, leading to thermal breakdown of the samples (Keiichi 1981).

In humid weather, moisture may diffuse into the polymer. The diffusion process normally is calculable by Fick's second law, provided the diffusion coefficient is independent of concentration and geometrical position. The diffusion characteristics may be determined by measuring the water vapour permeability of the sample. A general equation for calculating the water vapour permeability in steady state conditions is (Yamaguchi 1981)

$$
Q=P\left(\frac{P_{a}-P_{b}}{L}\right) t A,
$$

where $Q$ is quantity of water vapour transmission which is proportional to the charge measured by the coulometer (shown in figure 1 ), $P_{a}$ and $P_{b}$ are vapour pressures at the two film faces, $L$ is film thickness, $t$ time, $A$ area of film, and $P$ the permeability coefficient.

The water vapour permeability may be related to the diffusion and solubility coefficient by

$$
P=S D
$$

where $S$ is the solubility coefficient and $D$ the diffusion coefficient.

Table 2 shows the values of the permeability coefficient $(P)$, solubility coefficient $(S)$ and diffusion coefficient $(D)$ of PM, PMF-351 and PMF-352 polymer films at $20^{\circ} \mathrm{C}$ and $40^{\circ} \mathrm{C}$. It is observed from table 2 that the process of water vapour permeation 
Table 2. Permeability coefficient, diffusion coefficient and solubility coefficient of PM, PMF-351 and PMF-352 polymer films at different temperatures.

\begin{tabular}{lcccc}
\hline & \multicolumn{3}{c}{$\begin{array}{c}\text { Water vapour perm. } \\
\text { coeff. }\end{array}$} \\
Sample & $T\left({ }^{\circ} \mathrm{C}\right)$ & $P \times 10^{8} \mathrm{~g} / \mathrm{cm}$ h torr & $\begin{array}{c}\text { Diff. coeff. } \\
D \times 10^{6} \mathrm{~cm}^{2} / \mathrm{h}\end{array}$ & $\begin{array}{c}\text { Sol. coeff. } \\
9 \times 10^{2} \mathrm{~g} / \mathrm{cm}^{3} \text { torr }\end{array}$ \\
\hline PM & 20 & 0.92 & 3.0 & 0.30 \\
& 40 & 0.32 & 5.5 & 0.053 \\
PMF-351 & 20 & 0.25 & 1.2 & 0.213 \\
(polyimide to & 40 & 0.14 & 1.7 & 0.09 \\
water) & & & & \\
PMF-351 & 20 & 0.30 & 0.5 & 0.60 \\
(fluorocarbon & 40 & 0.20 & 1.6 & 0.10 \\
to water) & & & & \\
PMF-352 & 20 & 0.066 & 0.5 & 0.13 \\
& 40 & 0.12 & 1.9 & 0.066 \\
\hline
\end{tabular}

and diffusion into PMF-351 and PMF-352 polymer films are slower than the permeation and diffusion into PM polymer film. It is also important to mention here that the values of the permeation and diffusion coefficients are different on the two sides of the PMF-351 polymer film, i.e. this dual behaviour shows the polyimide on one side and fluorocarbon on the other side. Different breakdown mechanisms may occur on the two sides of the PMF-351 polymer film in humid conditions under the electric stress due to the difference in water permeation and diffusion characteristics, (table 1 and figure 3).

It is also observed from table 2 that the value of the water vapour permeability coefficient decreases and the value of diffusion coefficient increases with increase in temperature. In general, permeation, diffusion and solubility of vapour may be regarded as thermally activated processes, expressed by the following equations of the Arrhenius type (Van Krevelen 1976):

$$
\begin{aligned}
& D=D_{0} \exp \left(-E_{D} / R T\right), \\
& P=P_{0} \exp \left(-E_{P} / R T\right) \\
& S=S_{0} \exp \left(-E_{S} / R T\right),
\end{aligned}
$$

where $D_{0}, P_{0}, S_{0}$ and $E_{D}, E_{P}, E_{S}$ are constants for the particular gas and polymer.

The higher diffusion coefficient at $40^{\circ} \mathrm{C}$ may be the reason for the lower breakdown strength of the sample in $40^{\circ} \mathrm{C}+95 \%$ R.H. condition (figures 2,3 and 4). Figures 5 and 6 show the water vapour transmission curves for PM and PMF-352 polymer film. Before the measurement, samples were kept at $20^{\circ} \mathrm{C}+65 \%$ R.H., $20^{\circ} \mathrm{C}+95 \%$ R.H. and $40^{\circ} \mathrm{C}+95 \%$ R.H. for 6 months. The amount of charge measured by the coulometer can be converted into the quantity of water vapour transmission by the relation (Reithlinger 1974),

$$
M=\frac{9 Q}{96,500} \mathrm{~g} / \mathrm{h},
$$

where $M$ is the quantity of water vapour permeation through the film and $Q$ the amount of charge measured by the coulometer. 




Figure 5. Time dependent permeation of water vapour through PM polymer film at different humid conditions, $P=5 \times 10^{3}$ torr.

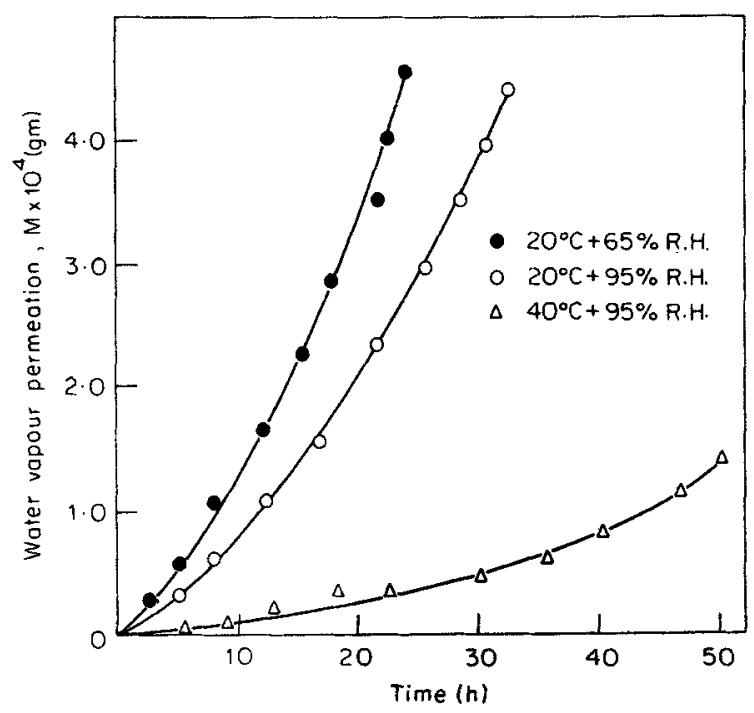

Figure 6. Time dependent permeation of water vapour through PMF-352 polymer film at different humid conditions, $P=5 \times 10^{3}$ torr.

It is observed from the figures that the rate of water transmission is slower at the more humid conditions $\left(20^{\circ} \mathrm{C}+95 \%\right.$ R.H. and $40^{\circ} \mathrm{C}+95 \%$ R.H.) than at the dry condition $\left(20^{\circ} \mathrm{C}+65 \%\right.$ R.H. $)$.

The water molecules present in the humid conditions diffuse into the polymer film. The increase in number of water molecules increases the clustering of water in the 
Table 3. Permeability coefficient, diffusion coefficient and solubility coefficient of $P M$ and PMF-352 polymer films at different weathering conditions.

\begin{tabular}{|c|c|c|c|c|c|c|}
\hline \multirow[t]{3}{*}{ Condition } & \multirow{2}{*}{\multicolumn{2}{|c|}{$\begin{array}{c}\begin{array}{c}\text { Perm. coeff. } \\
P \times 10^{8} \mathrm{~g} \mathrm{~cm} \mathrm{~h}\end{array} \\
\text { Sample }\end{array}$}} & \multirow{2}{*}{\multicolumn{2}{|c|}{$\frac{\begin{array}{c}\text { Diff. coeff. } \\
D \times 10^{6} \mathrm{~cm}^{2} / \mathrm{h}\end{array}}{\text { Sample }}$}} & \multicolumn{2}{|c|}{$\begin{array}{c}\text { Sol. coeff. } \\
S \times 10^{2} \mathrm{~g} / \mathrm{cm}^{3} \text { torr }\end{array}$} \\
\hline & & & & & & mple \\
\hline & $\mathbf{P M}$ & PMF-352 & $\mathbf{P M}$ & PMF-352 & $\mathbf{P M}$ & PMF-352 \\
\hline $20^{\circ} \mathrm{C}+65 \%$ R.H. & 1.0 & $0-07$ & $3 \cdot 5$ & 0.7 & 0.28 & $0 \cdot 10$ \\
\hline $20^{\circ} \mathrm{C}+95 \%$ R.H. & 0.90 & $0-05$ & $2 \cdot 5$ & 0.6 & $0 \cdot 36$ & 0.09 \\
\hline $40^{\circ} \mathrm{C}+95 \%$ R.H. & 0.50 & $0-01$ & $1-4$ & 0.3 & 0.32 & $0-04$ \\
\hline
\end{tabular}

polymer (at polar "centres" or in microcavities) so as to render part of the water comparatively immobile (Van Krevelen 1976). As a result, the major part of permeable water molecules in the PM and PMF polymer films seems to diffuse by way of a detour. Then the permeation path in the humid conditions is actually longer than that in the dry conditions, so longer time is taken for permeation in the humid conditions than in the dry conditions.

Table 3 shows the values of permeation coefficient $P$, diffusion coefficient $D$ and solubility coefficient $S$ for PM and PMF-352 polymer films. It is seen from the table that the values of permeation and diffusion coefficient decrease with increase in humidity.

A water molecule is bound by one hydrogen bond to the ether oxygen. There is no possible site for another hydrogen within the same polyimide chain. The water molecule can, however, make a bridge between adjacent polyimide chains. A hydrogen bond to another water molecule is unlikely as the maximum concentration of water molecule is only about two water molecules per three PM repeat units. The arrangement that may cause the asymmetric double potential well (Melcher et al 1989) as a result of decreasing permeation and diffusion coefficient on the other hand increases the dielectric breakdown strength (figures 2 and 4).

\section{Conclusion}

It is clear from the experimental results that humidity affects both the dielectric breakdown strength and the diffusion characteristics of polymer materials. Different kinds of diffusion characteristics and dielectric breakdown mechanisms are observed on the two sides of PMF-351 polymer film. The water vapour permeation and the diffusion process are slower into the polyimide fluorocarbon polymer than the simple polyimide film due to the upper fluorocarbon layer in the former. In humid conditions, there is increased clustering of water in the polymer. As a result permeable water molecules seem to diffuse by way of a detour. In $40^{\circ} \mathrm{C}+95 \%$ R.H. conditions, the permeation process is slower while on the other hand the dielectric strength is higher, which may be due to the formation of asymmetric double potential well in the polymer. 


\section{References}

Keiichi M 1981 Jpn. J. Appl. Phys. 202325

Malkin A, Askadsky A, Chalykh A and Kovriga V 1983 Experimental methods of polymer physics (Moscow: Mir publishers)

Melcher J, Yang D and Arlt G 1989 IEEE Trans. Electr. Insul. 2431

Reithlinger S A 1974 Pronishaemosth polimernix materialob (Moscow: Chimia)

Teckniceskue Yslovia 6-05-1491-1972 (USSR)

Techniceskue Yslovia 6-19-226-1983 (USSR)

Van Krevelen D W 1976 Properties of polymers, their estimation and correlation with chemical structure (Amsterdam, Oxford, New York: Elsevier Scientific Publ. Co.)

Yamaguchi H 1981 Proc. fifteenth electrical/electron insulator conference, Chicago, New York, p. 159 